\title{
Cuidar de pessoas com deficiência: um estudo junto a cuidadores assistidos pela estratégia da saúde da família*
}

\author{
Care of people with disabilities: a study with \\ caregivers assisted of the family health program
}

\author{
Marjorie Heloise Masuchi ${ }^{1}$, Eucenir Fredini Rocha ${ }^{2}$
}

\begin{abstract}
MASUCHI, M. H.; ROCHA, E. F. Cuidar de pessoas com deficiência: um estudo junto a cuidadores assistidos pela estratégia da saúde da família. Rev. Ter. Ocup. Univ. São Paulo, v. 23, n. 1, p. 89-97, jan./abr. 2012.
\end{abstract}

RESUMO: O artigo traz resultados de pesquisa que buscou compreender a tarefa que envolve o cuidar de pessoas com deficiência. Ele tem como foco os cuidadores de pessoas com deficiência, moradores das regiões de Vila Prudente e Sapopemba, São Paulo (Brasil), abrangidas pelas ações da estratégia da Saúde da Família - 2000 a 2007. Foram realizadas dezessete entrevistas compostas por questões abertas, nove com os profissionais da equipe de reabilitação e oito com os cuidadores de pessoas com deficiência. O objetivo foi entender o perfil dos cuidadores no que se refere à idade, sexo, escolaridade, religiosidade, grau de parentesco, atividades realizadas para o cuidado da pessoa com deficiência, bem como seus projetos para o futuro, mudanças ocorridas após tornar-se cuidador e suas redes de apoio. A análise das entrevistas dos cuidadores revelou que o cuidado é realizado - na maioria das vezes - por mulheres com idades entre 40 e 50 anos, que se dedicam integralmente ao cuidar da pessoa com deficiência. Da mesma maneira, a análise das entrevistas da equipe de profissionais de reabilitação, forneceu dados sobre o entendimento destes a respeito do cuidador, quais são suas necessidades e ações desenvolvidas pela equipe voltadas para esta população. Conclui-se que o cotidiano dos cuidadores é permeado por conflitos e agravos nas condições de saúde que devem ser mais bem observados pela equipe de saúde, uma vez que o cuidador é parte integrante do cuidado prestado à pessoa com deficiência e o mesmo acaba, muitas vezes, não sendo visto pelos profissionais de saúde como um sujeito que está sob constante tensão e carece de ações voltadas às suas questões.

DESCRITORES: Saúde da família, Pessoas com deficiência, Cuidadores; Entrevistas como assunto/métodos.

\footnotetext{
* Monografia apresentada à disciplina MFT0254 - Iniciação à Pesquisa II - Campo: Terapia Ocupacional e Saúde da Pessoa Portadora de Deficiência do curso de graduação em Terapia Ocupacional da Faculdade de Medicina da USP, 2007.

1. Terapeuta Ocupacional, docente do Curso de Terapia Ocupacional da Faculdade de Medicina do ABC. E-mail: marjorie_masuchi@ yahoo.com.br

2. $\operatorname{Prof}^{\mathrm{a}} \mathrm{Dr}^{\mathrm{a}}$, docente do Departamento de Fisioterapia, Fonoaudiologia e Terapia Ocupacional da Faculdade de Medicina da Universidade de São Paulo. E-mail: eucenir@usp.br

Endereço para correspondência: Rua Cipotânea, 51 - Cidade Universitária. CEP. 05360-160 - São Paulo - SP.
} 


\section{CONTEXTUALIZANDO}

$\mathrm{E}$ sse artigo relata os resultados de pesquisa de iniciação científica realizada em 2007 junto à cuidadores de pessoas com deficiência, moradores de Vila Prudente e Sapopemba, região sudeste do município de São Paulo, e profissionais de reabilitação da estratégia da Saúde da Família de nove Unidades Básicas de Saúde desse território. Objetivou-se entender como o cuidado é realizado, como os profissionais de saúde compreendem as necessidades dos cuidadores, as principais características dessas pessoas, suas atividades, seus projetos pessoais, a rede social de apoio que dispunham e as relações existentes com a pessoa com deficiência.

Desde 2000 a estratégia da saúde da família desenvolveu nesse território proposta de intervenção que abarcava também atividades reabilitacionais da pessoa com deficiência e para tanto, contava com o apoio de uma equipe de nove profissionais da área - três fisioterapeutas, três terapeutas ocupacionais e três fonoaudiólogos - que trabalhavam em conjunto com as equipes de saúde da família das unidades básicas de saúde dessa região (ROCHA, 2006) ${ }^{(1)}$. As equipes de saúde da família e de reabilitação manifestavam preocupação constante com os cuidados dispensados aos cuidadores e nesse contexto é que a proposta desse estudo emergiu.

\section{O cuidar em sua complexidade}

O cuidar é definido no Dicionário Houaiss como fazer algo com atenção, cautela, tomar conta de outra pessoa ou de si próprio e prevenir-se (HOUAISS, 2001). A palavra 'cuidado' deriva do latim cura que tem como forma mais antiga a escrita 'coera', utilizada em um contexto que envolve relações afetivas, de amor e amizade (BOFF, 1999).

Para Boff (1999, p.33) “cuidar é mais que um ato, é uma atitude. Portanto abrange mais que um momento de atenção, de zelo e de desvelo. Representa uma atitude de ocupação, de preocupação, de responsabilidade e de envolvimento afetivo com o outro".

Também está relacionado ao "entrar em sintonia com, auscultar-lhes o ritmo e afinar-se com ele" (p.96). Assim, o autor afirma que o cuidado ocorre quando a existência de uma pessoa tem importância para a outra, no caso, o cuidador. Isto implica no reconhecimento do outro como alguém singular.

Heidegger (1995) discute que o cuidado está sempre relacionado ao outro, e é entendido como ocupação e preocupação para além da pessoa que cuida. Desta forma, o cuidado é empregado no sentido de preservação do outro, vai além da atitude, compreende no modo-de-ser essencial, sempre presente e irredutível à realidade, que faz com que as pessoas coexistam, convivam e interajam entre si.

De acordo com Mendonça (1998) o cuidado em domicílio aos doentes é uma prática antiga que sofre influência religiosa e civil e é exercida principalmente pelas mães e esposas.

Cabe ressaltar que o papel de cuidar não é natural do sexo feminino, ele foi atribuído historicamente às mulheres (GIACOMIN et al., 2005), uma vez que o espaço privado, o domicilio, foi destinado social e culturalmente a elas. Essa condição desencadeou uma relação das mulheres com o mundo através do cuidado, do "tomar conta de", e dessa maneira muitas delas se tornaram cuidadoras de pessoas com algum agravo de saúde residente em seu domicilio.

O cuidador tem o papel imprescindível e decisivo para a pessoa que está sendo cuidada. Ele pode auxiliar a pessoa a retomar e reintegrar suas atividades e participação social, administrar remédios, realizar o tratamento necessário, fazer higiene e curativos, facilitar a independência nas atividades da vida diária, promover a autonomia e a privacidade, além de oferecer afeto, escuta, carinho, compreensão e apoio emocional (CESCHINI, 2005; MAZZA, 2004; WANDERLEY, 2005).

\section{A institucionalização do cuidado: relações entre a pessoa cuidada e o cuidador}

Karsch (1998) caracteriza o cuidador como formal, aquele que têm formação específica na área e seu trabalho é remunerado e, cuidador informal para se reportar às pessoas que não possuem formação específica, sendo adquirida pela prática. Normalmente o cuidador informal é um membro da família ou da comunidade.

Azevedo (2006) faz uma discussão sobre os cuidadores formais e informais, que suscita questionamentos sobre a realidade dos cuidadores informais. Estes, na maioria

\footnotetext{
(1) Essas nove unidades básicas de saúde estavam sob a gerência administrativa da Fundação Zerbini, parceira da Secretaria de Saúde do município de São Paulo. O trabalho caracterizou-se pela implementação de uma proposta ampliada da saúde da família, ou seja, além das equipes de saúde da família, os equipamentos contavam com o apoio de equipes de saúde bucal, mental, de ambulatório de especialistas médicos e, a partir de 2000, de equipe de reabilitação).
} 
das vezes, convivem com os saberes popular e científico, tendo que conciliá-los.

Ceschini (2005) classifica o cuidado como preventivo, quando visa evitar o adoecimento ou o agravamento de doenças; terapêutico, quando acompanha o paciente até o recebimento da alta médica; paliativo, ao ter por objetivo tratar e cuidar do paciente - que não tem perspectiva de cura - a fim de melhorar sua qualidade de vida e a de sua família.

Encontra-se, ainda, na literatura autores da área da saúde que abordam temas como orientação dos cuidadores, verificação e discussão das atividades desempenhadas, atribuições, necessidades, condições dos cuidadores e representações sociais sobre o cuidado (AZEVEDO, 2006; BOCCHI, 2001; MAZZA, 2004; MENDES, 2005; MENDONÇA, 1998).

O ambiente familiar ainda é considerado, mesmo pelos cuidadores formais (MAZZA, 2004) como o melhor espaço de cuidado, pois impede a segregação, o isolamento, a depressão e a falta de carinho. No entanto, a atividade de cuidar no lar requer a adaptação dos demais papéis e funções dos familiares, sendo que seus projetos de vida, relações pessoais e sociais, geralmente são redimensionados (MENDONÇA, 1998; MENDES, 2005).

Mendonça (1998) afirma ainda que a maioria dos cuidadores refere não pensar na realidade e, portanto, não se preocupam antecipadamente, adotam uma atitude maternal; não colocam limites, além de vivenciarem a atividade com sentimentos de compaixão.

A complexidade do ato de cuidar no domicilio está relacionada com o quadro clínico, a capacidade de realizar o auto-cuidado, a autonomia, a condição emocional e a auto-estima da pessoa que está sendo cuidada e do cuidador. Muitas vezes, quando a demanda depositada no cuidador é alta ela provoca alterações no seu estado de saúde, causando alterações no sono, memória, concentração, disposição e controle emocional (MENDONÇA, 1998). Dessa maneira pode-se afirmar que o cuidador é um sujeito em situação de vulnerabilidade, que necessita de auxílio e apoio físico e emocional, pois vivencia momentos de sofrimento causados pela sobrecarga de suas atividades. No entanto, os serviços de saúde nem sempre estão preparados para apoiar esses indivíduos com informações adequadas sobre o ato de cuidar, além de não reconhecerem a necessidade de oferecer estratégias de apoio cotidiano a essas famílias.

\section{PROCEDIMENTOS METODOLÓGICOS}

Foram realizadas dezessete entrevistas compostas por questões abertas, realizadas no local de trabalho, no caso dos profissionais, e nas residências dos próprios cuidadores. Todas foram gravadas e transcritas para leitura e releitura no processo de análise. Nove entrevistas foram realizadas com os fisioterapeutas, fonoaudiólogos e terapeutas ocupacionais que compunha a equipe de reabilitação da estratégia da saúde da família e oito efetivadas com os cuidadores. Os cuidadores foram sorteados de uma lista de cada profissional, a previsão era de que seriam nove entrevistas, mas um deles não pode participar(2).

A entrevista com os profissionais objetivou identificar como os mesmos conceituam o cuidado domiciliar, como identificam as atividades executadas pelos cuidadores e quais são as necessidades que eles demandam dos serviços de saúde. Em relação às entrevistas com os cuidadores objetivou-se detectar a natureza das atividades do cuidar, a rotina, as redes de apoio e o impacto do cuidar no seu cotidiano e em sua saúde.

As entrevistas foram analisadas numa perspectiva qualitativa, em que se buscou "o desvelamento do sentido social que os indivíduos constroem em suas interações cotidianas" (CHIZOTTI, 1991, p. 80).

Apoiou-se no entendimento “(...) de comunicação como processo e não como um dado estático, e do discurso como palavra em ato (...)" (MINAYO, 1994, p.206). Assim, a análise compreendeu que os significados atribuídos ao cuidar permitem contradições, incoerências e imperfeições, particulares da vivência descrita e que o pesquisador, com relação à comunicação, deve compreender criticamente o sentido das falas, seu conteúdo manifesto ou latente e suas significações (CHIZZOTTI, 1991).

\section{ANÁLISE DOS RESULTADOS}

Os resultados obtidos nas entrevistas foram agrupados em oito eixos: 1 . O cuidado e o cuidador vistos pelos profissionais da equipe de reabilitação; 2. Quem são os cuidadores; 3. O cuidar como atividade de trabalho; 4. Cuidar, religiosidade e religião; 5 . Lazer, cultura e qualidade de vida do cuidador; 6 . As redes de apoio social na atividade do cuidar; 7. Mudanças frente ao cuidar e 8. Necessidades detectadas pelos cuidadores dos serviços de saúde.

(2) Termo de Consentimento Livre e Esclarecido, aprovado pelo Comitê de Ética da Faculdade de Medicina da USP e Comitê de Ética em Pesquisa da Secretaria Municipal de Saúde do Município de São Paulo, projeto CAAE 0109/6, Parecer no. 0028/06. 


\section{O cuidado e o cuidador vistos pelos profissionais da equipe de reabilitação}

A relação entre o ato de cuidar e o cuidador é consequência da história de vida de cada indivíduo envolvido, da dinâmica familiar existente entre cuidador e pessoa com deficiência. Para os profissionais entrevistados cuidar é dar atenção, é ter disponibilidade, doar-se e dedicar-se, é algo inevitável, além de ser um trabalho, como também definido pelos cuidadores em pesquisa de Mendonça (1998).

Todos os profissionais disseram entender como atividades dos cuidadores: suprir as necessidades básicas da pessoa cuidada, como por exemplo, higiene, banho, vestuário, alimentação; suprir carências; fornecer atenção; estimular a pessoa cuidada nas atividades da vida diária e da vida prática; além de proporcionar participação social, sempre lembrando em promover maior autonomia e independência no cotidiano.

Os profissionais, ao referirem sobre a atividade do cuidar mencionam as imperfeições e ambiguidades desse ato e como se relacionam com os sujeitos cuidadores. Ora tomam a defesa das necessidades da pessoa cuidada, relatam o cuidar realizado pelo familiar como um ato que não é realizado na sua plenitude e, em outros momentos, reconhecem que os próprios profissionais desencadeiam inúmeras demandas que devem ser respondidas pelo cuidador e, como consequência, essas ações podem contribuir no adoecimento dos mesmos. Afirmam que as relações estabelecidas entre cuidador e pessoa cuidada são permeadas por sentimentos de culpa, obediência, respeito, amor, dedicação, entre outros e que estão sobrecarregados no dia-a-dia:

(...) E aí tem essa relação de cuidado que às vezes chega a ser tão..., eles judiam um pouquinho da pessoa, falam que ele merece estar aí, que a gente pode até ter uma noção, mas eu acho que a gente não consegue interferir, no máximo a gente consegue entender, mas interferir eu acho muito difícil (...) (FT1)

(...) o cuidador ele é sobrecarregado de funções, porque ele tem que fazer os exercícios de fisio, tem que fazer as atividades que a TO indica, tem que dar medicamentos na hora certa, tem que virar, tem que dar banho, um monte de coisas ele é responsável, e ninguém olha para ele, a gente acaba esquecendo do cuidador (...) (Fisioterapeuta)

(...) o cuidador muitas vezes acaba adoecendo e a gente não percebe (...)(Fisioterapeuta)

Reconhecem também que o cuidador muitas vezes vive intensamente a vida da pessoa cuidada, tornando esta relação muito próxima e interdependente e que se tornam cuidadores tanto por falta de opção financeira, quanto por razões decorrentes da dinâmica familiar:
(...) porque eles assumem esse papel... é como se tivesse um vácuo no espaço, tudo o que ele viveu antes não existiu e o futuro também não existe (...) (Terapeuta Ocupacional) (...) geralmente ele é a pessoa que o cuidado pode conversar mais, eu tento mostrar isso, que essa relação pode ser uma relação mais alegre, se eles puderem conversar um pouco, trocar informações, lógico que vai depender do quanto que a pessoa está sendo cuidada conversa, ... mas a relação pode ser menos tensa, ter menos desgaste, depende do modo como as coisas se estabelecem (...) (Fonoaudiólogo).

O cuidador é entendido como um indivíduo que não procura atendimento regular para sua saúde, não realiza atividades de lazer, de trabalho ou qualquer outro tipo de atividade que não estejam relacionadas com as do cuidar do outro. Reconhecem que os serviços de saúde precisam oferecer espaços de atenção à saúde e qualidade de vida dos cuidadores, colaborar na articulação de redes de apoio social a esses indivíduos, mostrar a importância do convívio social, lazer, autocuidado, e, consequentemente das relações de cuidado.

\section{Quem são os cuidadores}

A região aonde os cuidadores residem concentra uma alta densidade populacional, um IDH muito baixo em relação ao restante do município, além de um alto índice de violência. Também foi constatado que a maior parte desta população recebe até cinco salários mínimos, o que dificulta o gasto com serviços de saúde, lazer, cultura ou a contratação de serviços de apoio ou asilares.

Com a realização das entrevistas, foi constatado que dos oito cuidadores entrevistados, dois são homens e seis são mulheres, sendo que, uma das mulheres recebe ajuda de seu esposo para cuidar de sua mãe. Todas as pessoas cuidadas moram com suas famílias de origem, com exceção de uma senhora que vive com o genro.

A faixa etária dos cuidadores variou em um intervalo de 34 anos a 78 anos e, a maioria estudou até o Ensino Fundamental incompleto.

Dentre os cuidadores entrevistados, somente uma deles recebe remuneração para prestar cuidados e outra cuidadora familiar tem o auxílio de uma diarista contratada para realizar as atividades relacionadas ao lar.

Com relação aos cuidadores do sexo masculino, um deles é cuidador de seu pai; outro cuida de sua esposa juntamente com a ajuda de filhos, netos e cunhada; e o terceiro auxilia sua esposa cuidar de sua sogra.

O grau de parentesco entre cuidadora e pessoa cuidada na maioria dos casos são mãe e filha, sendo que 
as filhas cuidam das mães e, mesmo nos casos em que há homens nas casas, as mulheres são as que executam a maior parte das atividades de cuidado.

\section{O cuidar como atividade de trabalho}

Segundo Garcia (2004, apud SENA et al., 2006) o cuidar "trata-se de um trabalho quase sempre nãoremunerado, com base em relações afetivas e de parentesco e que pertence ao terreno do privado: assuntos de família, que o restante da sociedade não valoriza do ponto de vista econômico". (p.126).

O trabalho vai além do ato de trabalhar e receber remuneração; ele proporciona sentimento de pertencimento a algum grupo social; é um continuum que influencia todas as esferas da vida do indivíduo (LANCMAN; GHIRARDI, 2002). Ao não ser reconhecido, o cuidador, acaba sendo desqualificado e seu trabalho não apresenta importância social, e o mesmo perde parte de sua identidade e de crédito perante a família e sociedade.

(...) nossa...minha família não acredita em mim, quando eu vou contar uma coisa ninguém escuta, sabe...meu cunhado sentou aqui e disse que eu estou numa boa que eu só estou cuidando do meu pai, sabe...pensa que é fácil, não é assim não, tá louco, eles chegam aqui, vê ele sentado aqui, todo bonitinho e o resto eles não vê, eles não sabem o trabalho que dá para cuidar dele...eu não aguento mais...como eu te falei, no começo eu não dormia, é tudo muito difícil, entendeu? Eu vou levando, o que eu posso fazer? (...) (A.)

Para a cuidadora remunerada, além do trabalho prover sustento para ela e sua família, ele a faz se sentir bem, útil, proporcionando prazer e reconhecimento. No entanto, nenhum outro cuidador citou como trabalho atual 'o cuidar da pessoa com algum tipo de deficiência'. Ao contrário citaram outras atividades profissionais como fazer cortinas para vender, costurar, agente comunitária de saúde, auxiliar de enfermagem, mesmo não exercendo essas atividades no momento da entrevista. Tal fato pode ser decorrente da dificuldade do cuidador familiar ser reconhecido e se reconhecer como um trabalhador, pois muitos veem a atividade de cuidar como um dever moral decorrente das relações pessoais e familiares (MENDES, 2005).

Alegaram ainda, que não conseguem trabalhar fora de suas casas por falta de tempo, por não contarem com ajuda de outras pessoas para realizar as atividades de cuidar, e devido à relação estabelecida com a pessoa cuidada e desse modo fica evidente que o ato de cuidar é desvalorizado pelos outros membros da família e das relações sociais.

\section{Cuidar, religiosidade e religião}

Apesar da literatura ressaltar que a religião tem importância fundamental na sustentação emocional, instrumental e informativa, além de inúmeras implicações nos processos de saúde e adoecimento (FARIA; SEIDL, 2005), pois crenças em um ser superior, a fé, a espiritualidade e as práticas religiosas são estratégias eficazes de muitos cuidadores para minimizar a sobrecarga, a angústia, do estresse e depressão decorrentes do processo de cuidar, nas entrevistas realizadas, os cuidadores não se detiveram nesses aspectos.

Dos entrevistados, $50 \%$ são da Igreja Católica, sendo que somente um não a frequenta, $37,5 \%$ são da Igreja Evangélica e todos disseram que a visitam com frequência, somente um cuidador disse não ter mais religião.

Apesar da maioria ter religião, ao serem questionados se participam ou não, a maioria diz ir somente quando tem tempo, justificando o afastamento das atividades religiosas decorrente dos compromissos com a pessoa cuidada, à limitada rede de apoio e às condições reais do cotidiano dos cuidadores.

\section{(...) Assim, depois que meu marido teve AVC, menos...} mas sempre que dá eu vou (...) (M.)

Aspectos pessoais relacionados à fé não foram citados nos depoimentos, apenas a dificuldade de participar das atividades promovidas pela igreja, mais relacionadas às atividades sociais da prática religiosa.

\section{Lazer, cultura e qualidade de vida do cuidador}

Na sociedade contemporânea toda e qualquer outra atividade humana não relacionada ao trabalho não é significativa e assim, não necessita ser realizada (DUMAZEDIER, 1976), além disso, as atividades de lazer e cultura estão inter-relacionadas a gastos. $\mathrm{O}$ acesso a essas atividades na Vila Prudente e Sapopemba pressupõe deslocamentos para outras regiões, o que nem sempre é possível para os cuidadores entrevistados, pois dispõem de poucas condições financeiras.

Percebeu-se que os cuidadores familiares possuem uma vida bastante restrita ao lar e agravada por diminuída rede de apoio familiar. Além disso, a vida cotidiana é bastante comprometida em sua qualidade. Dois dos cuidadores demonstraram a falta de liberdade até em seu domicílio, uma vez que o casal cuida da pessoa com 
deficiência dentro de seu próprio quarto e, assim, não possuem momentos sozinhos.

\section{(...) a única coisa é dar uma esfriadinha na cabeça. Por exemplo, sair, entendeu? Pegar um final de semana aí...(...) E para a gente é pior ainda, porque ela dorme dentro do nosso quarto, ai acaba que a coisa fica mais tensa (...) Aí você não consegue sair no portão para respirar, aí você está dentro de casa e você não consegue ter uma liberdade dentro de casa.Fica tudo mais complicado... (...) (P. e P.)}

As atividades de lazer foram descritas pelos cuidadores como aquelas restritas às festas comemorativas que são realizadas em suas próprias casas, por ser uma maneira de reunir a família e realizarem encontros sociais com a sua participação e da pessoa cuidada.

\section{As redes de apoio social na atividade do cuidar}

(...) eu vou ser sincera, eu cuido porque é minha mãe, porque senão eu não cuidava mais, porque eu já cuidei também de uma velhinha daí de cima ..., mas eu também era mais nova. Eu cuido porque é minha mãe, senão eu não cuidava não. Porque ocupa muito a cabeça da gente, a gente fica muito estressada, e eu também passei por uns problemas aí muito grave, então é uma coisa muito séria, chegou na síndrome do pânico meu estado, eu estava ruim mesmo (...) (S.)

Dessen et al. (2000) discute que os suportes sociais recebidos e percebidos pelas pessoas são fundamentais para a manutenção da saúde mental e enfrentamento de situações estressantes com o intuito de proporcionar alívio dos estresses físico e mental.

Desta maneira, ao possuir uma rede de apoio, o cuidador poderá ser beneficiado tanto física quanto mentalmente, o que promoverá melhor qualidade de vida.

Em seu estudo, Sena et al. (2006) constataram que o cuidado, na maioria das vezes, é exercido por apenas uma única cuidadora e estas "afirmam que se sentem, muitas vezes, sozinhas e com uma carga de responsabilidade superior à que imaginavam suportar." (p. 130).

Felgar (1998, apud KARSCH, 1998) verificou que $39,6 \%$ dos cuidadores solicitaram ajuda aos familiares para cuidar do paciente e, este auxílio foi minimizado conforme o cuidador passou a assumir as atividades de cuidado junto à pessoa cuidada.

Assim, os autores concluem que a atividade do cuidador domiciliar acaba sendo "um ato solitário $e$ permanente agravado pela precariedade dos recursos físico, econômico e de apoio social, evidenciando os limites de um fazer que se concretiza no cotidiano entremeado por relações de afetividade, compromisso e dedicação" (p. 131).

Desta maneira, percebe-se a importância do estabelecimento de uma rede mínima de suporte social para que o cuidador possa realizar, além das atividades destinadas ao cuidar, atividades para seu autocuidado, entretenimento, entre outras. Verifica-se que tais redes são imprescindíveis para que o cuidador possa manter e/ou promover qualidade de vida, evitar situações de estresse e adoecimento físico e emocional ao dividir responsabilidades e sobrecargas com os demais membros que compõe a rede de apoio social.

Poucos são os cuidadores que têm apoio familiar e/ ou outro para compartilhar os cuidados oferecidos à pessoa cuidada. Tal fato intensifica a anulação do cuidador como um indivíduo que possui vontades e projetos de vida, uma vez que sua vida estrutura-se na da pessoa cuidada.

Neri (1993 apud NERI, 2002) ressalta que "grande parte do ajustamento às tarefas e ao papel de cuidar depende de recursos pessoais que podem ser aprendidos e dos apoios de que o cuidador dispõe ou que sabe solicitar. Estas condições tendem a funcionar como amortecedores do impacto negativo da situação do cuidar sobre o bem-estar do cuidador" (p.161).

Com relação às relações dos cuidadores e pessoas com deficiência, verifica-se que estas são relações unilaterais, pois, nem sempre há trocas entre os indivíduos resultando em uma exacerbação da sobrecarga do cuidador e anulação de suas atividades de autocuidado e interesses, bem como um estreitamento de sua participação social.

Esta sobrecarga gerada pelas atividades do cuidar, tanto aos cuidadores que somente realizam esta tarefa, quanto aos que trabalham e/ou prestam serviços geram sentimentos de obrigação aos cuidadores.

Os entrevistados narraram se sentirem muito sós, com apouco apoio dentro da família e menos ainda por parte de outras relações e equipamentos sociais. A solidão vivenciada desencadeia diferentes e ambíguos sentimentos, como amor, ódio, gratidão, compaixão e solidariedade.

(...) mas de resto sou tudo eu...então assim, eu acho que eu sou um pouco assim, é...é...como se diz, é...não é bem a palavra insubstituível, mas assim, eu não gosto assim de chamar as pessoas para vir olhar a E. porque eu acho que a E. é um problema meu entendeu? (...) (D.) 
Atenção e cuidados por parte dos serviços de saúde são fundamentais. Nenhum profissional relatou estratégias específicas para intervir na direção de articular possibilidades de apoio individual ou coletivo aos cuidadores nas unidades básicas de saúde. Reconhece-se a necessidade de intervenções que atendam as necessidades dos cuidadores, mas, por parte dos profissionais prevalecem ações de orientação verbal em relação aos cuidados e dicas sobre o "melhor" comportamento dos cuidadores.

\section{Mudanças frente ao cuidar}

Cada indivíduo possui sua maneira de vivenciar e lidar com a vida, independentemente do estilo de vida que as pessoas levam, ao passar por experiências pessoais e/ ou familiares de processos de adoecimento, na maioria das vezes suas rotinas são modificadas.

Comumente, a mudança da rotina dos indivíduos é drástica e devem ser re-estruturadas para a nova fase em que se tornam cuidadores de pessoas com algum tipo de deficiência.Quando questionados sobre as mudanças ocorridas durante o processo de cuidar e as atividades realizadas, os cuidadores relataram ser estas as que mais os sobrecarregam, causam estresse e aumentam a preocupação com a pessoa cuidada.

(...) ah mudou tudo, mudou, né, porque primeiro eu gostava de sair com a turma, agora eu não saio mais porque estou ocupada, eu fico mais aqui com ela... ih, mudou tudo (...) (S.)

(...) ah, mudou, mudou assim, tem uma preocupação que a gente tem, né? Quando a gente sai, a gente se preocupa. Eu me preocupo do estado dela quando ela fica nervosa, eu me preocupo mais com ela do que com todos (...) (S.)

Ao mesmo tempo em que causam tais sentimentos, estas relações são as que provocam um distanciamento entre cuidador, família, vizinhança e sociedade.

(...) a gente meio que ficou assim distanciado do mundo (...) (P.e P.)

Azevedo (2006) constatou que a perda de privacidade e de momentos de lazer podem contribuir para um aumento da desorganização psíquica e assim, uma dificuldade de reorganização e re-construção da vida.

Desta maneira, constata-se que mudanças na rotina e relações entre familiares, cuidador e pessoa com deficiência são inevitáveis e esperadas. Entretanto, sua naturalização não deve ser estimulada, pois, ao tornar-se um cuidador de pessoa com deficiência, as pessoas normalmente ficam sobrecarregas e diminuem suas atividades do cotidiano para seu bem-estar e lazer, ocasionando agravamento de saúde física e mental, bem como distanciamento da família e da sociedade.

\section{Necessidades detectadas pelos cuidadores dos serviços de saúde}

Os cuidadores relataram sobre a necessidade de haver um carro para o transporte dos pacientes às suas consultas no posto; o aumento de visitas domiciliares realizadas tanto pelos profissionais da reabilitação quanto pelos médicos e odontólogos; e o aumento do número de profissionais de reabilitação.

Uma cuidadora discutiu sobre a necessidade da existência de um atendimento mais especializado. Ela refere não ter suporte adequado além de não conseguir atendimento em hospitais devido o quadro atual da filha.

(...) não tem um suporte, e você leva para o Pronto Socorro, eles fazem um exame de sangue, de fezes... Não mesmo, problema, entendeu, aí vai. Se vai de novo e faz...e assim... Não é só isso, você não tem um lugar específico para você levar na rede pública, que fala assim, 'não, olha... tem pessoas especializadas (...) (D.)

Mendonça (1998) afirma que é preciso integrar os cuidadores no sistema de saúde, ou seja, reconhecê-los como coadjuvantes do processo de cuidar, reconhecer que estão marginalizados, tem grande sobrecarga de sofrimento e não são reconhecidos em suas atividades, precisam de ajuda, apoio e orientação.

Verificou-se na pesquisa que os serviços da região não estão preparados para atender integralmente a pessoa cuidada e seu cuidador, apesar das equipes de saúde da família contar com o apoio de profissionais de reabilitação. As ações de saúde devem ser planejadas para o atendimento de diferentes demandas desses usuários - cuidador e cuidado - de maneira que o cuidador possa se sentir acolhido e contemplado em suas necessidades de saúde física e mental, possa contar com ações intersetoriais capazes de suprir as outras demandas do cotidiano desses usuários, como transporte, lazer, cultura, entre outras, de maneira a lidarem com as condições que colocam essa população em situação de vulnerabilidade.

\section{CONSIDERAÇÕES FINAIS}

O cotidiano dos cuidadores é permeado por constante tensão devido à intensidade das relações e quantidade dos cuidados com a pessoa com deficiência (AZEVEDO, 2006) e muitas vezes eles abdicam de suas histórias de vida, de suas rotinas e de atividades de lazer e cultura para exercerem as 
atividades do cuidar, tornando-se pessoas isoladas ou com contato social restrito.

Sabe-se ainda que o cuidador, em geral, não possui redes de apoio que oportunizem sua participação nos espaços sociais de troca, de cultura e de cuidados, tornando-se, assim, também vítima das experiências de estigmatização, segregação e exclusão social vivida pelas pessoas com deficiência (GOFFMAN, 1988; ROCHA, 2006).

Essa condição torna o cuidador vulnerável e trata-se, desse modo, de mais um dos desafios para os profissionais da área da saúde, proporcionar e promover ações voltadas ao cuidador, para que as atividades do cuidado não sejam atividades adoecedoras, mas sim, realizadas concomitantemente com outras atividades da história de vida de cada indivíduo.

Os cuidadores são os principais auxiliares da equipe de reabilitação e de saúde da pessoa com deficiência, pois, cuidador é quem está o maior tempo possível junto à pessoa cuidada, seja realizando atividades de autocuidado, higiene ou reabilitação.

Ao tentar entender como ocorrem as relações de cuidado, foi percebida uma modificação dos papéis sociais e familiares dos atores envolvidos, causando dependência, infantilização e sobrecarga do cuidador devido sua responsabilização, obrigação e necessidade de satisfazer todos os interesses da pessoa cuidada.

Sendo assim, constata-se que o cuidador assume diferentes responsabilidades decorrentes da tarefa do cuidar e acaba não possuindo rede de apoio familiar e social adequadas.

Por meio das entrevistas com os profissionais da equipe de reabilitação, torna-se clara a preocupação destes com o cuidador e a redução de suas atividades, além da necessidade da existência de programas voltados para os mesmos. Por outro lado, as ações para a melhoria das condições de saúde do cuidador ainda são pioneiras e precisam ser elaboradas e aprimoradas para que realmente os cuidadores sejam alvos destas e consigam se beneficiar do serviço de saúde.

Para haver um real atendimento destinado aos cuidadores, é necessário articular redes de apoio social e equipamentos existentes na própria comunidade a fim de garantir que o cuidador possa buscar atendimento para sua saúde, sem a preocupação de que a pessoa cuidada ficará sozinha ou não assistida.

Por fim, conclui-se que é necessário desenvolver ações que atendam as diversas e reais demandas dos cuidadores, para que estes tenham maior autonomia e conhecimento das atividades desenvolvidas no cuidar e não tenham suas vidas limitadas e restritas nesta tarefa.

A promoção de saúde é abordada na estratégia da saúde da família como um conceito ampliado de saúde, ou seja, é entendida como forma de garantir um cuidado integral por meio da co-responsabilização entre comunidade e instituições. Além disto, visa reduzir danos, internações, a vulnerabilidade dos sujeitos em relação ao adoecimento e o consumo exacerbado de medicamentos. Entendemos que a saúde da família, que tem sua estrutura centrada na família, deve oferecer ações para todos os integrantes da mesma.

MASUCHI, M. H.; ROCHA, E. F. Care of people with disabilities: a study with caregivers assisted of the family health program. Rev. Ter. Ocup. Univ. São Paulo, v. 23, n. 1, p. 89-97, jan./abr. 2012.

\begin{abstract}
The study presents research results that aimed to clarify the task related to the care of people with disabilities. It focuses on caregivers of people with disabilities, residents of the Vila Prudente and Sapopemba areas, São Paulo (Brazil), covered by the "Family Health Program” (PSF) from 2000 to 2007. Thus, it was taken seventeen interviews consisting of open questions: nine of them with the professional rehabilitation team and the other questions with caregivers of people with disabilities. The goal was to understand the caregivers ` profile regarding age, gender, education level, religion, relationship, activities realized for the care of people with disabilities, as well as their future projects, changes related to what happened after becoming caregiver and their support network. The analysis of the caregiver's interview showed that the care is carried out - most of the time - by women with ages between 40 and 50 years, that dedicated themselves full time to the care people with disabilities. In the same way, the investigation of the professionals of the team's interview gave data about their understanding of the caregivers, which are their needs and actions developed by the team to this population. It was concluded that the caregivers daily is permeated by conflicts and problems that should be better observed by the health team, since the caregiver is part of the care provided to the person with disability and frequently he himself often ends not seen as a person who is under constant stress and who needs help of his own issues.
\end{abstract}

KEYWORDS: Family health; Disabled persons, Caregivers, Interviews as topic/methods. 


\section{REFERÊNCIAS}

AZEVEDO, G. R.; SANTOS, V. L. C. G. Cuida-dor (D)eficiente: as representações sociais de familiares acerca do processo de cuidar. Rev. Latino-amer. Enferm., v. 14, n. 5, 2006.

BOCCHI, S. C. M. Movendo-se entre a Liberdade e a Reclusão: vivendo uma experiência de poucos prazeres ao vir-a-ser um familiar cuidador de uma pessoa com AVC. [Tese] - Escola de Enfermagem da Universidade de São Paulo, São Paulo, 2001.

BOFF, L. Saber cuidar: ética do humano - compaixão pela terra. Rio de Janeiro: Vozes, 1999.

CESCHINI, M. Por que assistência domiciliar. In: DIAS, E. L. F.; WANDERLEY, J. S.; MENDES, R. T. (orgs.) Orientações para cuidadores informais na assistência domiciliar. Campinas: UNICAMP, 2005.

CHIZZOTTI, A. Pesquisa em ciências humanas e sociais. São Paulo: Cortez, 1991.

DESSEN, M. A.; BRAZ, M. P. Rede social de apoio durante transições familiares decorrentes do nascimento de filhos. Rev. Psic: Teoria Pesq., v. 16, n. 3, 2000.

DUMAZEDIER, J. Lazer e cultura popular. São Paulo: Perspectiva, 1976.

FARIA, J. B.; SEIDL, E. M. F. Religiosidade e enfrentamento em contextos de saúde e doença: revisão da literatura. Psicol. Reflex. Crit., v. 18, n.3, 2005.

FELGAR, J. A. S. Uma expressão da linguagem numérica. In: KARSCH, U. M. C. (org). Envelhecimento com dependência: revelando cuidadores. São Paulo: EDUC, 1998.

GARCÍA-CALVENTE M. M.; MATEO-RODRIGUEZ, I.; EGUIGUREN, A. P. El sistema informal de cuidados em clave de desigualdad. In: SENA, R. R.; SILVA, K. L.; RATES, H. F.; VIVAS, K. L.; QUEIROZ, C. M.; BARRETO, F. O. O cotidiano da cuidadora no domicílio: desafios de um fazer solitário. Cogitare Enferm., v. 11, n. 2, p. 124-32, 2006.

GIACOMIN, K. C.; UCHOA, E.;LIMA-COSTA, M. F. F. Projeto Bambuí: a experiência do cuidado domiciliário por esposas de idosos dependentes._Cad. Saude Publica, Rio de Janeiro, v. 21, n. 5, p. 1509-1518, 2005.

GOFFMAN, E. Estigma - notas sobre a manipulação da identidade deteriorada. Rio de Janeiro: Guanabara, 1988.

HEIDEGGER, M. Ser e tempo. Petrópolis: Vozes, 1995.

HOUAISS, A.; VILLAR, M. S. Minidicionário Houaiss da língua portuguesa. Rio de Janeiro: Objetiva, 2001.

KARSCH, U. M. C.; LEAL, M. G. S. Pesquisando cuidadores: visita a uma prática metodológica. In: KARSCH, U. M. C. (org). Envelhecimento com dependência: revelando cuidadores. São Paulo: EDUC, 1998.

LANCMAN, S.; GHIRARDI, M. I. G. Pensando novas práticas em terapia ocupacional, saúde e trabalho. Rev. Ter. Ocup. Univ. São Paulo, v. 13, n. 2, p. 44-50, 2002.

MAZZA, M. M. P. R.; LEFÈVRE, F. A instituição asilar segundo o cuidador familiar do idoso. Saúde Soc., v. 13, n. 3, p. 68-77, 2004.

MENDES, P. B. M. T. Quem é o cuidador? In: DIAS, E. L. F.; WANDERLEY, J. S.; MENDES, R. T. (orgs.) Orientações para cuidadores informais na assistência domiciliar. Campinas: UNICAMP, 2005.

MENDONÇA, M. K. A realidade dos cuidadores: assistência em domicílio aos portadores de câncer. 1998. 173f. [Dissertação] Universidade Federal de Mato Grosso do Sul.

MINAYO, M. C. S. O desafio do conhecimento - pesquisa qualitativa em saúde. $3^{\text {a }}$.ed. São Paulo: HUCITEC, 1994.

NERI, A. L., PERRACINI, M. R. Tarefas de cuidar: com a palavra, mulheres cuidadoras de idosos de alta dependência; In: NERI, A. L. Cuidar de idosos no contexto da família: questões psicológicas e sociais. São Paulo: Alínea, 2002.

ROCHA, E. F. (Org). Reabilitação de pessoas com deficiência a intervenção em discussão. São Paulo: Roca, 2006.

SENA, R. R.; SILVA, K. L.; RATES, H. F.; VIVAS, K. L.; QUEIROZ, C. M.; BARRETO, F. O. O cotidiano da cuidadora no domicílio: desafios de um fazer solitário. Cogitare Enferm., v. 11, n. 2, p. 124-132, 2006.

WANDERLEY, J. S. Introdução. In: DIAS, E. L. F.; WANDERLEY, J. S.; MENDES, R. T. (Orgs.). Orientações para cuidadores informais na assistência domiciliar. Campinas: UNICAMP, 2005.

Data de entrada: 02/04/2012

Data de aprovação: 19/04/2012 